\title{
Effects of water recirculation rate on the microbial community and water quality in relation to the growth and survival of white shrimp (Litopenaeus vannamei)
}

Zhao Chen ${ }^{1,2}$, Zhiqiang Chang ${ }^{1}$, Long Zhang ${ }^{1}$, Yuli Jiang ${ }^{2}$, Hongxing Ge', Xiefa Song ${ }^{2}$, Shibo Chen ${ }^{3}$, Fazhen Zhao ${ }^{1}$ and Jian $\mathrm{Li}^{1 *}$

\begin{abstract}
Background: Microbial community and its management are crucial to the stabilization of culture environment for recirculating aquaculture system (RAS). Although several studies have been carried out for the microbial community of RAS, few studies were on the RAS for shrimp. Water recirculation ratio is an important factor for the microbial community and the management of RAS. Therefore, low (LC), medium (MC) and high (HC) recirculation ratio systems were set to explore the microbial community constitution of RAS for Litopenaeus vannamei and study the effect of water recirculation rate on it.

Results: The bacterial community of bioreactor was mainly dominated by Proteobacteria (41.6-70.7\%), followed with Planctomycetes (12.5-31.0\%), Bacteroidetes (10.5-26.0\%), Actinobacteria (1.1-4.8\%) and Verrucomicrobia (1.46.8\%) phylum. The most dominant family of bioreactor was Rhodobacteraceae or Planctomycetaceae. The bacterial community of culture water was simpler than bioreactor and dominated by Proteobacteria (61.8-96.4\%). The dominant bacterial groups of bioreactor and culture water are also different among the three water recirculation rates, and the proportions of dominant groups showed a trend with the variety of water recirculation rate. Water quality indexes including ammonia and nitrite decreased with the increasing of water recirculation rate. According to the growth performance of L. vannamei, shrimp had better performance of growth rate and final weight in MC and HC, however, shrimp had higher survival and yield in LC. Shrimp survival and yield had an inverse correlation with water recirculation rate.

Conclusions: The results demonstrate the microbial community of RAS for shrimp, highlight the importance of further studies on the function of bacterial taxa, and promote the understanding of the effects of water recirculation rate on the microbiota. The findings suggest that water recirculation rate has important impacts on the microbial community, water quality and shrimp growth. Increasing the water recirculation rate could improve the water quality and promote the growth of shrimp. However, the survival rate and yield of L. vannamei are higher under low water recirculation rate. Recirculation rate is an effective method to manage RAS, and its impact on RAS needs further study, especially in the application of low level of water recirculation.
\end{abstract}

Keywords: RAS, Recirculation ratio, HRT, Litopenaeus vannamei, Biofilm, Bacterial community

\footnotetext{
* Correspondence: lijian@ysfri.ac.cn

${ }^{1}$ Key Laboratory for Sustainable Development of Marine Fisheries, Ministry of

Agriculture, Yellow Sea Fisheries Research Institute, Chinese Academy of

Fishery Sciences, Qingdao 266071, People's Republic of China

Full list of author information is available at the end of the article
}

(c) The Author(s). 2019 Open Access This article is distributed under the terms of the Creative Commons Attribution 4.0 International License (http://creativecommons.org/licenses/by/4.0/), which permits unrestricted use, distribution, and reproduction in any medium, provided you give appropriate credit to the original author(s) and the source, provide a link to the Creative Commons license, and indicate if changes were made. The Creative Commons Public Domain Dedication waiver (http://creativecommons.org/publicdomain/zero/1.0/) applies to the data made available in this article, unless otherwise stated. 


\section{Background}

In response to increasing demand for aquaculture products and a strict requirement on aquaculture wastewater discharge, land-based recirculating aquaculture system (RAS) is being developed as a viable eco-sustainable alternative to traditional aquaculture because of its minimal environmental impact and controlled culture condition [1]. After a long period of development, the technology of RAS gradually matures in fish culture. RAS is also feasible and available for shrimp culture [25] whereas its application is relatively scarce in shrimp culture. The shrimp farming industry is an important component of world aquaculture [6]. Nevertheless, shrimp farming also suffered from many problems as traditional aquaculture, including disease outbreaks, environmental degradation, and poor management [5, 79]. The Pacific white shrimp (Litopenaeus vanname) is one of the major shrimp farming species and is adaptive to intensive farming for its strong adaptability. RAS is a well alternative mode for L. vanname culture.

The microorganism is crucial to the stability of the aquaculture environment in RAS. The biofilter is a microbial purification link of RAS and acts to remove nitrogenous waste byproducts generated by fish protein catabolism and oxidation processes [10]. However, biofilter is a complicated black box, and the understanding of its action mechanism is incomplete. As for the efficiency of the biofilter, the primary determinants are the communities and abundances of the functional microbial groups established within the filter, which determine the final results [11]. Microorganisms in culture water are also important for the stability of the aquaculture environment and the health of aquaculture organisms since they could directly contact with culture organisms. Therefore, information on the bacterial community and diversity in biofilters and culture water would be useful for the design and operation of RAS [12, 13].

The understanding of the internal structure of biofilters is gradually increased with many studies about the microbial community in biofilters and culture water have been done [13-20]. Various factors could affect the microbial community [14, 17], which include culture species and hydraulic retention time (HRT). HRT directly related to water recirculation ratio or flow rate and is an important factor for microbial community structure $[14,21-23]$ and biofilters efficiency [24, 25]. However, most studies of HRT was merely about reactors rather than based on aquaculture system, much less about RAS of shrimp. To maintain the well aquatic environment RAS adopt high water recirculation ratio (more than 20 cycles per day) [26-29], since high recirculation ratio is in beneficial to remove nitrite, ammonia and solid particle $[24,25]$. However, high water recirculation ratio means high energy consumption. Besides, $L$. vanname has a stronger tolerance to nitrite and ammonia $[30,31]$ than fish and could be cultured in turbid water with the mass of suspended particles. Therefore, RAS of shrimp could adopt low water recirculation ratio for energy conservation. It's necessary to carry out studies on the effects of water recirculation ratio on the microbial community for improving the management of microorganism in the recirculating shrimp culture system.

The objective of the present study was to characterize the bacterial community in the water and on the filters of biofilters, and explore the effects of water recirculation rate on the microbial community, water quality and shrimp, and determine the relationship of microbial community, water quality with shrimp growth and survival. And thus, improving the management of RAS for L. vannamei.

\section{Results}

Microbial community composition of the bioreactor

The bacterial community in the bioreactor was mainly composed of Proteobacteria (41.6-70.7\%), Planctomycetes (12.5-31.0\%), Bacteroidetes (10.5-26.0\%), Actinobacteria (1.1-4.8\%) and Verrucomicrobia (1.4-6.8\%) phylum (Fig. 1), which account for probably $98 \%$ of the total bacteria in frequency. Proteobacteria dominated all bioreactor communities in the experiment.

Microbial community composition changed with time. At the phylum level, the percentage of Proteobacteria reduced from $61.9-70.7 \%$ to $41.6-53.5 \%$ (Fig. 1a, Fig. 1b). At the family level, the dominant bacteria group turned from Rhodobacteraceae (30.2-49.6\%) to Planctomycetaceae (16.01-30.14\%) (Fig. 2a, Fig. 2b). Besides, the frequency of dominant families presented a trend with water recirculation rate and was significantly affected by it $(P<0.05)$.

At the genus level, $30-50 \%$ of the bacteria belong to unclassified or other bacteria whose abundance was very low. In the midterm (Fig. 3a), the most dominant genus was Ruegeria, accounting for $18.2-34.6 \%$ of total bacteria. Nitrosomonas was the only nitrobacteria detected in all bioreactors with the frequency of $0.2-1.0 \%$. At the end of culture (Fig. 3b), the Ruegeria was not the dominant genus anymore. And the dominant genus was different in $\mathrm{LC}, \mathrm{MC}$ and $\mathrm{HC}$. In $\mathrm{LC}$, the most dominant genus was Gimesia (13.5\%), while in MC, the dominant genus including Spongiibacterium (7.0\%), Blastopirellula (7.0\%) and Gimesia (6.5\%), and in HC, the dominant genus including Blastopirellula (5.4\%), Planctomicrobium (4.6\%) and Gimesia (4.2\%). The proportion of dominant genus was declined with the rise of water recirculation. Three kinds of nitrobacteria were detected in the end including Nitrococcus $(0.0-0.6 \%)$, Nitrosomonas $\quad(0.2-0.8 \%)$ and Nitrospira $(0.0-0.3 \%)$. The 

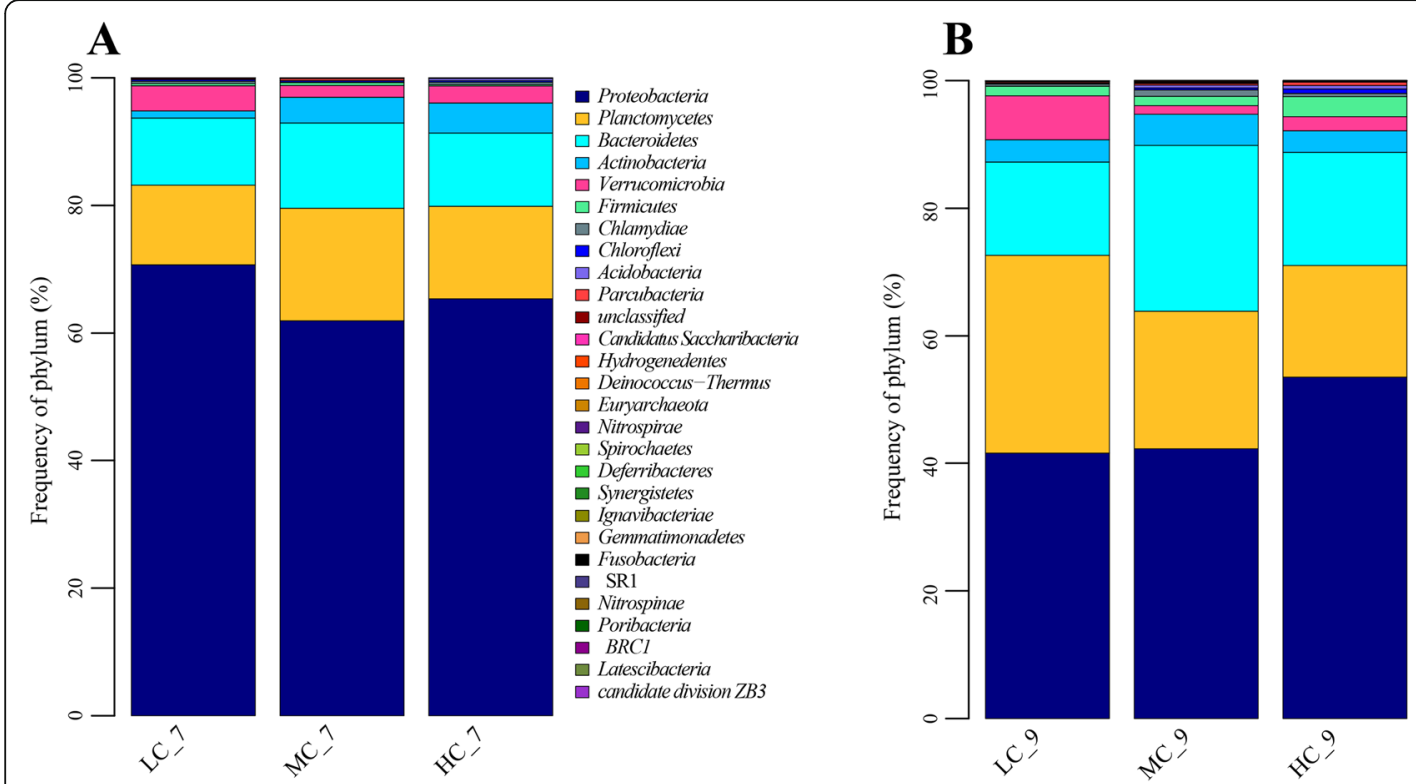

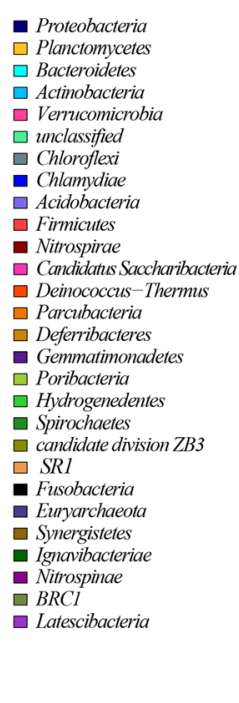

Fig. 1 Taxonomic assignment of bacteria in the bioreactor at phylum level shown as a percentage of the total microbiota. a and $\mathbf{b}$ are the microbial community structure in midterm (July) and terminal (September) of the experiment respectively

proportion of nitrobacteria, in the end, was more than that in the midterm. Vibrio as potential pathogeny whose percentage was increased from $0.1-1.1 \%$ in the midterm to $0.5-3.6 \%$ in the end. And the proportions of Vibrio in bioreactors were declined with the rise of water recirculation $(P<0.05)$ in the end.

\section{Microbial community composition of culture water}

As shown in Fig. 4, the bacteria composition of culture water was simpler than that of the bioreactor. At the phylum level, the bacteria community was mainly composed of Proteobacteria and Bacteroidetes, which roughly accounted for $98 \%$ of the total bacteria. Meanwhile, both the proportion of Proteobacteria and Bacteroidetes was affected by water recirculation $(P<0.05)$. Furthermore, at family and genus level, all proportions of dominant groups presented a trend with water recirculation rate.

At the family level, the bacteria community was mainly dominated by Rhodobacteraceae (15.6-48.0\%), Colwelliaceae (0.4-26.2\%), Alteromonadaceae (5.2-25.0\%), Pseudoalteromonadaceae (2.6-32.6\%) and Flavobacteriaceae
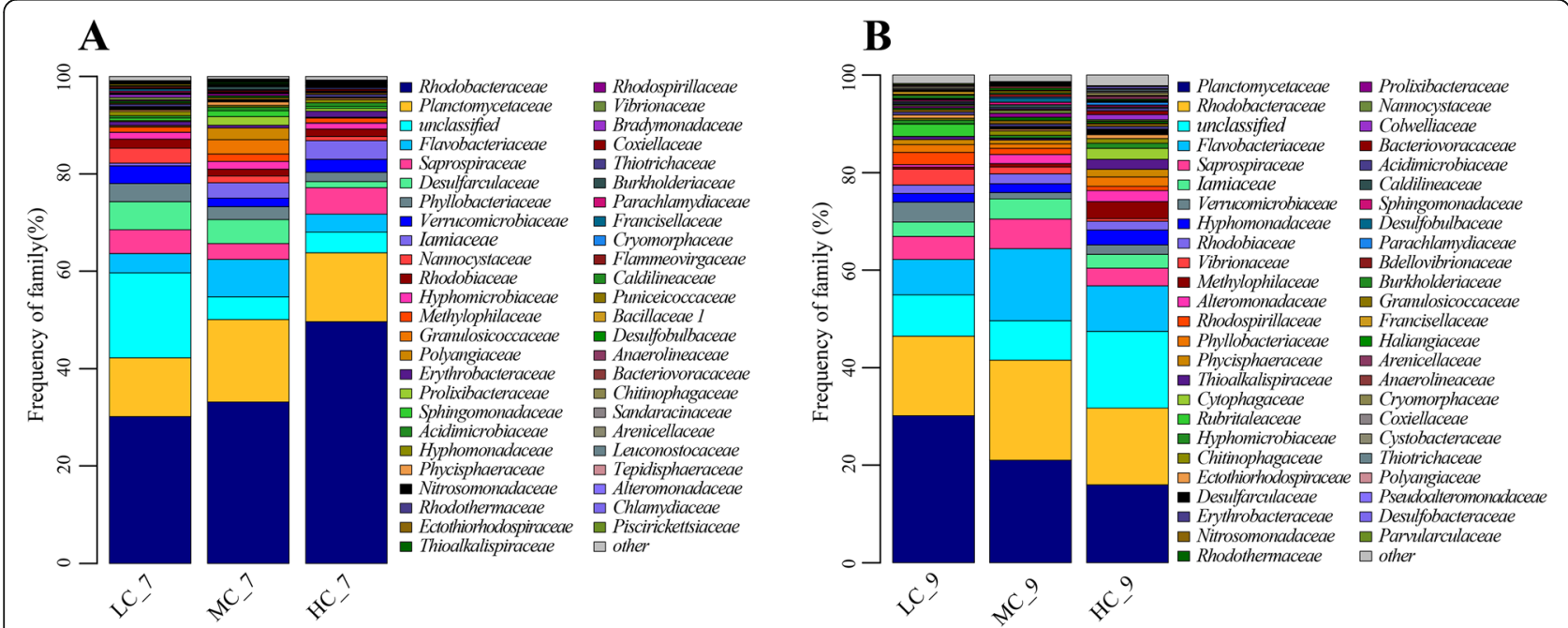

Fig. 2 Taxonomic assignment of bacteria in the bioreactor at the family level shown as a percentage of the total microbiota. $\mathbf{a}$ and $\mathbf{b}$ are the microbial community structure in the midterm (July) and terminal (September) of experiment respectively 

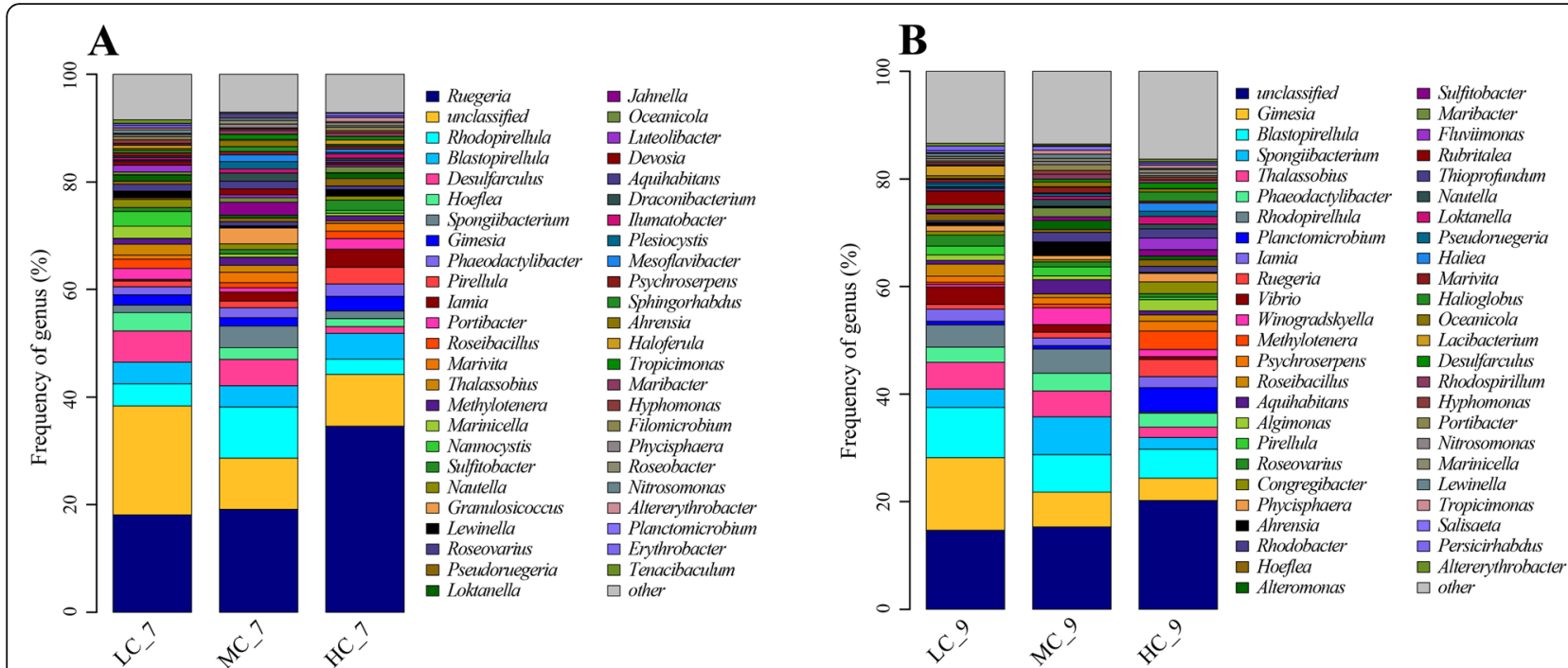

Fig. 3 Taxonomic assignment of bacteria in the bioreactor at genus level shown as a percentage of the total microbiota. a and $\mathbf{b}$ are the microbial community structure in the midterm (July) and terminal (September) of experiment respectively

(1.6-32.1\%). The five families roughly accounted for $90 \%$ of the total bacteria. The frequencies of Rhodobacteraceae and Flavobacteriaceae were declined with the rise of water recirculation. However, the frequencies of Colwelliaceae and Pseudoalteromonadaceae were increased with the rise of water recirculation. And Alteromonadaceae had the highest frequency in MC. Besides, the proportion of Flavobacteriaceae was significantly affected by water recirculation $(P<0.05)$.

At the genus level, the dominant bacterial community was composed of Nautella (12.2-44.6\%), Thalassotalea (0.3-26.2\%), Pseudoalteromonas (2.5-31.4\%), Aestuariibacter (2.2-22.2\%) and Tenacibaculum (0.5-14.0\%). The sum proportion of the five genera accounted for 62.5$82.8 \%$. And the frequency of other portion which had very low abundance was less than $2.5 \%$. All the frequencies of five dominant genera showed a trend impacted by water recirculation. The dominant genus was different in $\mathrm{LC}, \mathrm{MC}$ and $\mathrm{HC}$. In LC, the dominant genera were Nautella (44.6\%) and Tenacibaculum (14.0\%), while in MC, the dominant genera including Aestuariibacter (22.2\%), Thalassotalea (21.1\%) and Nautella (21.2\%), and in HC, the dominant genera including Pseudoalteromonas (31.4\%), Thalassotalea (26.2\%), Aestuariibacter (12.4\%) and Nautella (12.2\%). Nitrosomonas and Nitrospira were detected in culture water. But the proportion was less than $0.1 \%$. The frequency of potential pathogen Vibrio was about $1.5 \%$.

\section{The diversity of the microbial community}

$43,805-71,225$ sequences with an average of 55,410 were detected in one bioreactor sample or culture water sample (Table 1). 744-1272 OTUs with an average of 1026 could be obtained from one sample. There was no significant difference $(P>0.05)$ between bioreactor samples and culture water samples in sequence and OTU number.

According to the Chaol index, the abundance of bacteria in bioreactors had no significant difference $(P>0.05)$ among $\mathrm{LC}, \mathrm{MC}$ and $\mathrm{HC}$ or between midterm and terminal of the experiment. But the bacterial diversity in the terminal was higher than that in the midterm according to Simpson index. In addition, the diversity of the bacterial community in bioreactors was all higher than that in culture water. There was a significant difference of bacterial community among bioreactor samples in the midterm and end, and culture water samples in the end (Fig. 5). Besides, the difference between bioreactor samples and culture water samples was more. The water recirculation rate had a significant effect on bacterial diversity. In the midterm, bacterial diversity in $\mathrm{HC}$ was the lowest, however, in the end, $\mathrm{HC}$ had the highest bacterial diversity. According to Fig. 6, the water recirculation rate had different effects on the microbial community diversity of bioreactor and culture water. In bioreactors, $\mathrm{LC}$ and $\mathrm{MC}$ had more similar $\beta$-diversity. However, in culture water, $\mathrm{MC}$ and $\mathrm{HC}$ had more similar $\beta$-diversity.

\section{Water quality}

As to the temperature, salinity, $\mathrm{DO}$ and $\mathrm{pH}$ during the whole experimental period, there were no significant differences $(P>0.05)$ among the three groups at different recirculation rate. However, the turbidity, vibrio count, and the concentration of ammonia and nitrite in the LC group were significantly higher $(P<0.05)$ than those groups with higher water recirculation rate (Tables 2 


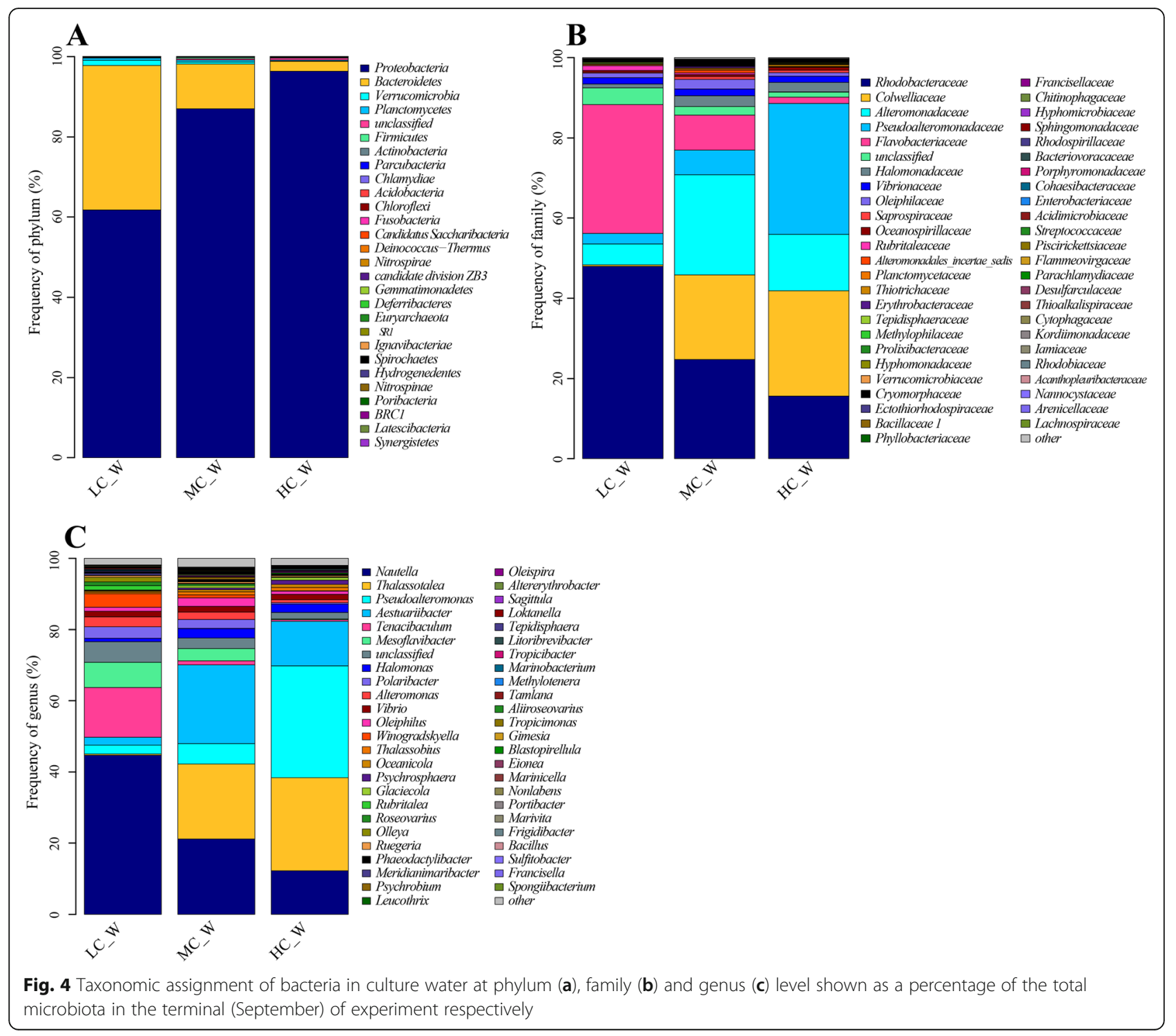

and 3). The peak concentration of TAN and nitrite were 1.69 and $7.32 \mathrm{mg} \mathrm{L}^{-1}$ in LC, 0.72 and $3.87 \mathrm{mg} \mathrm{L}^{-1}$ in $\mathrm{MC}, 0.81$ and $2.81 \mathrm{mg} \mathrm{L}^{-1}$ in $\mathrm{HC}$, respectively.

The Pearson correlation analysis showed there was a significant correlation between water quality indexes of ammonia $(\mathrm{r}=-0.913, P<0.05)$, nitrite $(\mathrm{r}=-0.988, P<$ $0.01)$ and turbidity $(\mathrm{r}=-0.928, P<0.01)$ and water recirculation rate. Increased flow rate showed a decreasing trend in ammonia, nitrite and turbidity as shown in the regression analysis in Fig. 7. The Vibrio number also showed a decreasing trend with the increasing of water recirculation rate, but there was no significant correlation $(P>$ 0.05 ) between them due to the great variation of Vibrio.

\section{Growth performance of shrimp}

At harvest, significant differences were observed in final average weight, SGR, survival, and harvest yield among the three treatments (Table 4). FCR also showed some differences among the treatments, but there was no significant difference among the treatments due to the variance within the treatments.

The growth performance of shrimp was affected by water quality. The Pearson correlation analysis showed that there was a correlation between shrimp weight and ammonia concentration $(r=-0.676, P<0.05)$, and between shrimp weight and Vibrio number $(r=-0.869$, $P<0.01)$. There was no significant correlation between shrimp weight and nitrite concentration. Increasing water recirculation rate was helpful to improve water quality and promote shrimp growth. However, there was a significant inverse linear relationship $\left(R^{2}=0.77, P<\right.$ 0.05 ) between survival and water recirculation rate (Fig. 8). The survival rate of shrimp decreased with the increase of water recirculation rate. The harvest yield 


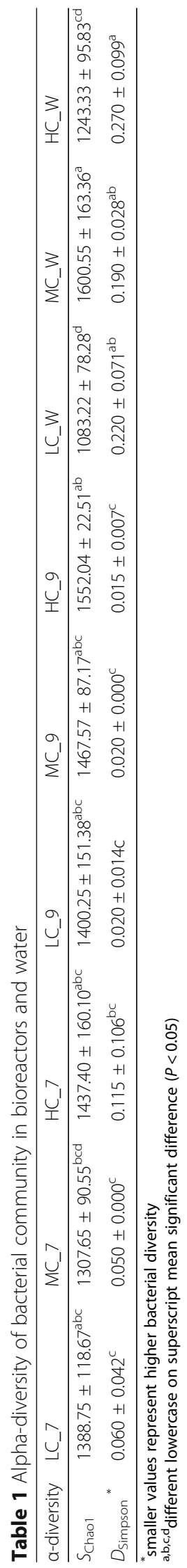




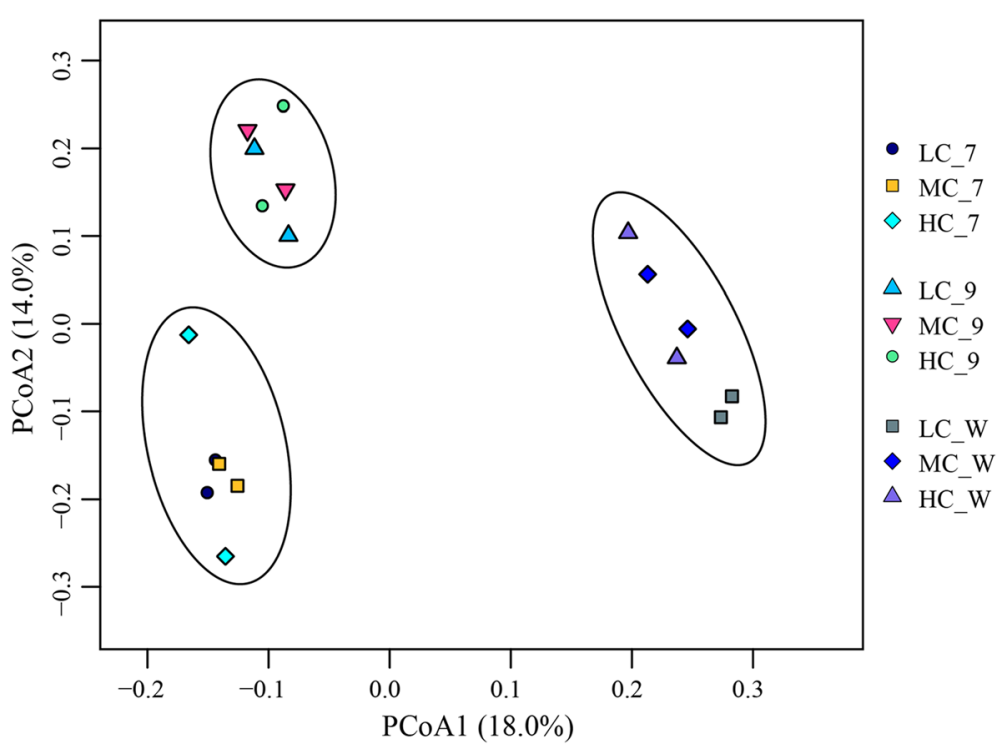

Fig. 5 UPGMA tree of Bray-Curtis distances in the genus

and FCR also showed the inverse trend with water recirculation ratio in spite of no significant linear relationship was observed $(P>0.05)$.

\section{Discussion}

\section{Microbial community structure of biofilter}

The communities and abundances of the functional microbial groups are the primary determinants for aquaculture condition [11]. Previously, low-coverage characterization methods (e.g., DGGE, clone libraries) was adopted to describe the taxa present in the microbial community, but the extent of this diversity and similarity among systems was relatively unknown. Massively parallel sequencing technology is an emerging and reliable method to study the

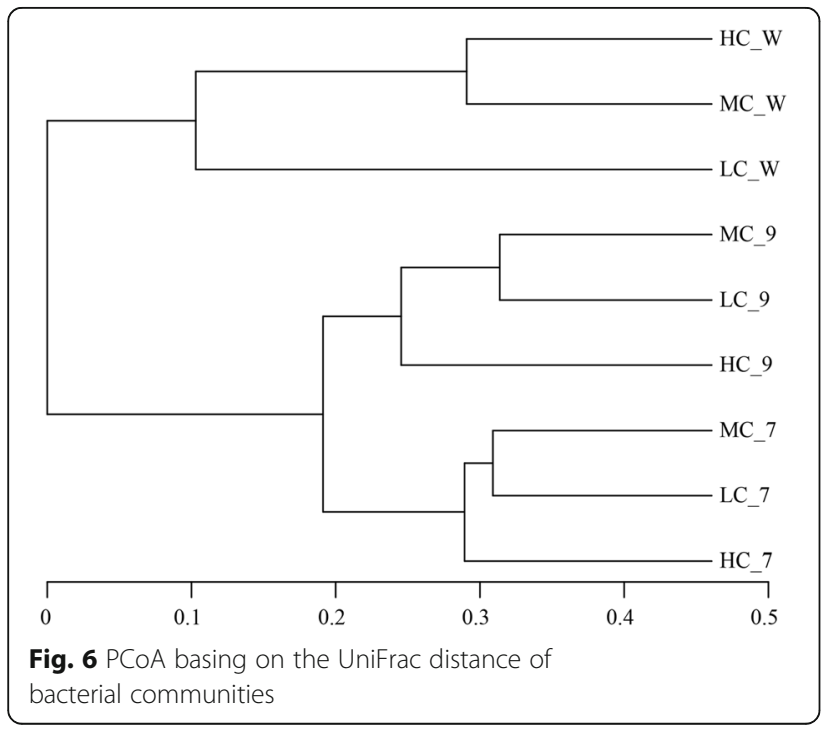

microbial community [32]. Figure 1 showed that the most dominant phylum was Proteobacteria, which was dominated by $\alpha$-Proteobacteria (27.0-56.9\%). Schreier [12] summarize the composition of the microbial community in recirculating aquaculture systems including Actinobacteria, Bacterioidetes/Chlorobi, Firmicutes, Nitrospirae, Planctomycetales, and Proteobacteria. At the phylum level, the microbial community composition has high similarity to the report of Schreier [12], as well as the research of Weitz [33] and Huang [16] in the biofilter. Proteobacteria is the most dominant phylum in RAS.

The taxonomic assignment of bacteria in bioreactors had many similarities to the previous reports at the phylum level. But with the decrease of classification level, the differences in the bacterial community increased gradually. Due to the limited understanding of the entire bacteria, there were $10-20 \%$ of the bacteria in bioreactors which were unclassified in the genus. And there were $20-30 \%$ of the bacteria whose proportion in the genus was lower than $1 \%$. The most dominant genus was Ruegeria (19.1-34.6\%) in the midterm, while in the end, the dominant genera included Gimesia (4.2-13.5\%), Blastopirellula (5.4-9.4\%) and Spongiibacterium (2.2$7.0 \%)$. The dominant genera were different from the reports of Schneider [14] and Ruan [13]. Rud fund that culture systems were dominated by Proteobacteria with Rhodobacteraceae as the dominating taxa, followed by Bacteroidetes that was dominated by Polaribacter among others [34]. Huang also reported that the microbial community composition was different among biofilters [16]. The dominant genera of this study were different from the reports above, much less the bacteria composition. A lot of factors could impact the bacterial community 
Table 2 Initial water quality

\begin{tabular}{llllllll}
\hline $\mathrm{T}\left({ }^{\circ} \mathrm{C}\right)$ & $\mathrm{Sal}\left(\mathrm{g} \mathrm{L}^{-1}\right)$ & $\mathrm{O}_{2}\left(\mathrm{mg} \mathrm{L}^{-1}\right)$ & $\mathrm{pH}$ & Turbidity (NTU) & Vibrio $\left(\mathrm{CFU} \mathrm{mL}{ }^{-1}\right)$ & $\mathrm{NH}_{4}{ }^{+}-\mathrm{N}_{\left(\mathrm{mg} \mathrm{L}^{-1}\right)}$ & $\mathrm{NO}_{2}{ }^{-} \mathrm{N}\left(\mathrm{mg} \mathrm{L}^{-1}\right)$ \\
\hline $27.85 \pm 0.5$ & $29.25 \pm 0.12$ & $6.32 \pm 0.31$ & $8.07 \pm 0.03$ & $0.00 \pm 0.00$ & $18.33 \pm 7.64$ & $0.01 \pm 0.00$ & $0.00 \pm 0.00$ \\
\hline
\end{tabular}

structure including DO [17], salinity [17], temperature [35], C/N ratio [36], cultured species [37], HRT [14], disinfection [33], etc. The microbial community in bioreactors is difficult to control [12, 38-40] and many of the inefficiencies of the system originate from this [41]. But the information on bacterial composition structure in biofilter is necessary, and the management of autotrophic and heterotrophic bacteria is the key factor to maintain good water quality and health of farmed organisms [42].

The reason why bioreactor could remove ammonia and nitrite is that of the bacteria community of biofilm. There are three validly described genera of the ammonia-oxidizing bacterium (AOB), Nitrosomonas, Nitrosospira and Nitrosococcus, and four genera of the nitrite-oxidizing bacterium (NOB), Nitrobacter, Nitrospina, Nitrococcus and Nitrospira, which contribute to the process of nitration. In this study, three genera of nitrobacteria were detected including Nitrococcus, Nitrosomonas and Nitrospira. But none of the proportion of nitrifier exceeded $1 \%$. It was different from previous reports $[13,16]$. The result of Huang showed that Nitrospira and Nitrosomonas were dominant nitrifiers in biofilters with the proportion of $0.2-16.4 \%$ and $0.1-$ $2.8 \%$, respectively. Ruan reported that the proportion of Nitrospira was $1.8-6.0 \%$, while the proportion of Nitrosomonas was less than $0.1 \%$ in the bioreactor of a fullscale marine RAS. In this study, RASs was for shrimp which had a shorter culture-cycle than fish. It could be the time limit result in the low frequency of nitrobacteria since the experiment sustained only 3 months. Other bacteria which not belong to traditional nitrobacteria may participate in the nitrogen cycle, such as Rhodobacteraceae [43-45] and Planctomycetaceae [46, 47]. On the other hand, the involvement of novel nitriteoxidizing species, which include Archaea, may contribute to nitration [12, 15, 48-50].

The function of dominant genera in bioreactors, Ruegeria, Gimesia, Blastopirellula and Spongiibacterium, is indefinite. Ruegeria belongs to Rhodobacteraceae. Lidbury reported that Ruegeria pomeroyi DSS-3 could contribute to the remineralization of nitrogen in the form of ammonium [45], and Choi reported Ruegeria pomeroyi has nos $Z$ sequence for $\mathrm{N}_{2} \mathrm{O}$ reduction [44]. Gimesia genus belongs to Planctomycetaceae and has only one species Gimesia maris which was called Planctomyces maris [46]. Gimesia maris is a chemoheterotroph growing on defined medium with glucose and ammonia as sole carbon and nitrogen sources respectively [51]. Blastopirellula genus belongs to Planctomycetaceae. Blastopirellula is chemoheterotrophic whose type species Blastopirellula marina could use ammonia, nitrate and organic nitrogen [52]. Spongiibacterium is a genus of Flavobacteriaceae [53]. In consideration of the low frequency of AOB and NOB in bioreactors, Rhodobacteraceae and Planctomycetaceae, which were the dominant families of bioreactors, may contribute more to the nitrogen conversion in RAS. The function of Rhodobacteraceae and Planctomycetaceae in aquaculture need further investigation.

\section{Microbial community structure of culture water}

Bacteria is an essential part of the breeding water which could direct contact with culture organism with lots of effects. Zheng reported that Proteobacteria and Bacteroidetes were widely distributed in healthy shrimp at all growth stages, but varied in relative abundance among different steps [54]. In this study, the composition of bacteria in culture water was mainly composed of Proteobacteria (61.8-96.4\%) and Bacteroidetes (2.5-36.0\%). However, at the genus level, the bacteria composition had a lot of difference from previously reports [54]. Nautella is a genus of Rhodobacteraceae. It was fund by Vandecandelaere, and has a great similarity to Roseobacter [55]. According to Zheng's study, Nautella is pathogen to L. vannamei for it had more proportion in the diseased water sample and could be an indicator for monitoring the health status of shrimp larvae in the hatchery $[54,56]$. The genus Thalassotalea was proposed by Zhang [57] with the description of Thalassotalea piscium as its type species and reclassification of four species of the genus Thalassomonas as members of the

Table 3 Temperature, salinity, $\mathrm{O}_{2}, \mathrm{pH}$, turbidity, vibrio, ammonia and nitrite of rearing water

\begin{tabular}{|c|c|c|c|c|c|c|c|c|}
\hline Treatment & $\mathrm{T}\left({ }^{\circ} \mathrm{C}\right)$ & Sal $\left(g \mathrm{~L}^{-1}\right)$ & $\mathrm{O}_{2}\left(\mathrm{mg} \mathrm{L}^{-1}\right)$ & $\mathrm{pH}$ & Turbidity (NTU) & Vibrio $\left(10^{3} \mathrm{CFU} \mathrm{mL}^{-1}\right)$ & $\mathrm{NH}_{4}^{+}-\mathrm{N}\left(\mathrm{mg} \mathrm{L}^{-1}\right)$ & $\mathrm{NO}_{2}-\mathrm{N}\left(\mathrm{mg} \mathrm{L}^{-1}\right)$ \\
\hline$\overline{L C}$ & $28.19 \pm 2.35^{a}$ & $29.62 \pm 0.43^{a}$ & $5.92 \pm 0.30^{a}$ & $7.91 \pm 0.35^{a}$ & $1.40 \pm 0.53^{\mathrm{a}}$ & $3.79 \pm 3.04^{a}$ & $0.67 \pm 0.46^{\mathrm{a}}$ & $3.23 \pm 2.44^{\mathrm{a}}$ \\
\hline$M C$ & $28.27 \pm 2.10^{\mathrm{a}}$ & $29.52 \pm 0.41^{a}$ & $6.12 \pm 0.22^{\mathrm{a}}$ & $8.02 \pm 0.38^{\mathrm{a}}$ & $0.81 \pm 0.24^{b}$ & $1.75 \pm 1.89^{b}$ & $0.39 \pm 0.16^{\mathrm{b}}$ & $2.06 \pm 1.11^{\mathrm{ab}}$ \\
\hline $\mathrm{HC}$ & $28.31 \pm 2.44^{\mathrm{a}}$ & $29.69 \pm 0.49^{a}$ & $6.03 \pm 0.23^{\mathrm{a}}$ & $8.10 \pm 0.45^{a}$ & $0.67 \pm 0.12^{b}$ & $2.04 \pm 2.09^{b}$ & $0.28 \pm 0.23^{b}$ & $1.26 \pm 0.82^{b}$ \\
\hline
\end{tabular}

$\overline{\mathrm{a}, \mathrm{b}}$ different lowercase on superscript mean significant difference $(P<0.05)$ 


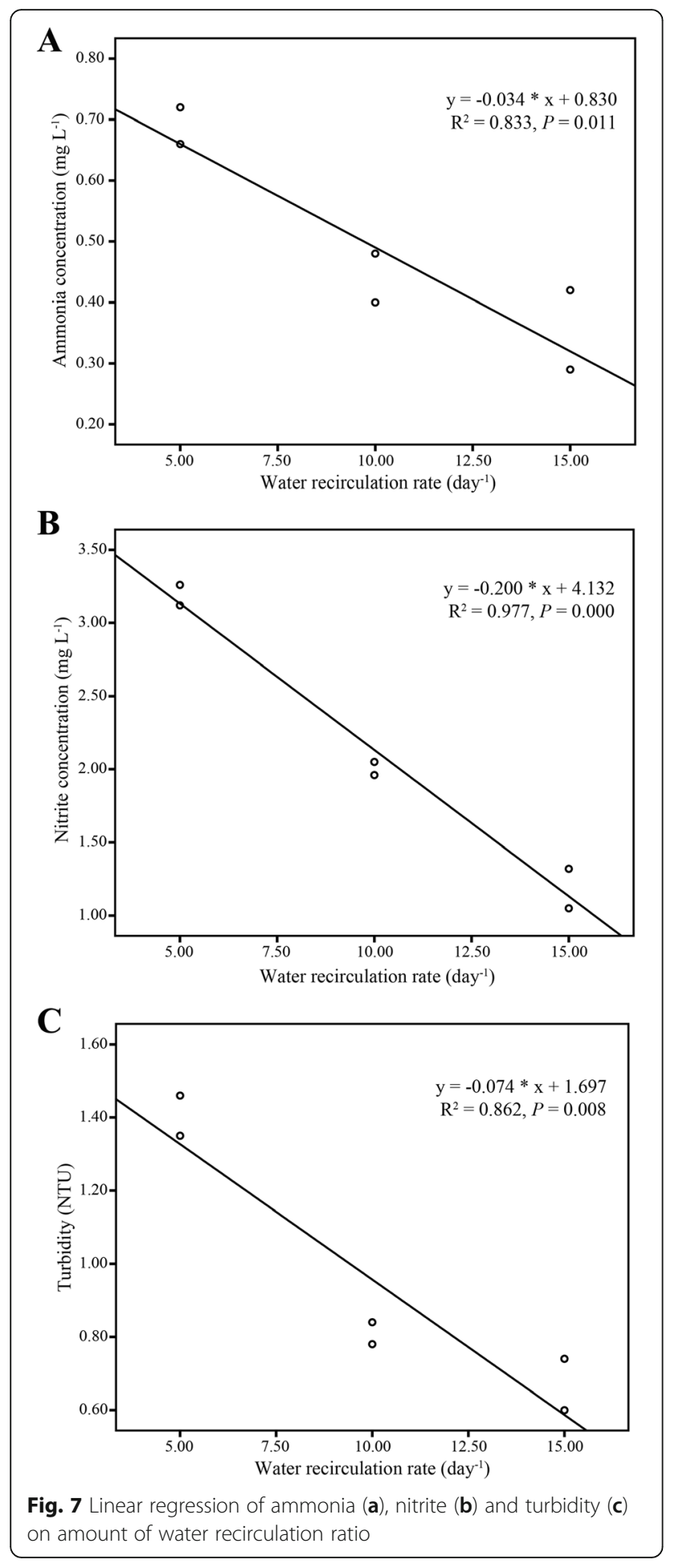

novel genus, and its description was amended by Park [58]. Hou isolated Thalassotalea marina sp. nov. from RAS of Epinephelus awoara [59]. But the relationship between Thalassotalea and the cultured organism is still unknown. Pseudoalteromonas is probiotics with the effects of reducing the larval mortality of fish and shrimp
Table 4 Growth performance of shrimp reared under different water recirculation ratio

\begin{tabular}{llll}
\hline Variable & \multicolumn{3}{l}{ Treatment } \\
\cline { 2 - 4 } & LC & MC & HC \\
\hline Final weight (g) & $6.78 \pm 2.40^{\mathrm{c}}$ & $9.91 \pm 4.26^{\mathrm{a}}$ & $8.42 \pm 3.33^{\mathrm{b}}$ \\
SGR (\%) & $4.8 \pm 0.4^{\mathrm{b}}$ & $5.2 \pm 0.5^{\mathrm{a}}$ & $5.0 \pm 0.4^{\mathrm{a}}$ \\
Survival (\%) & $66.2 \pm 10.4^{\mathrm{a}}$ & $42.5 \pm 3.1^{\mathrm{b}}$ & $37.9 \pm 0.9^{\mathrm{b}}$ \\
Harvest yield $\left(\mathrm{kg} \mathrm{m}^{-3}\right)$ & $1.51 \pm 0.33^{\mathrm{a}}$ & $1.39 \pm 0.05^{\mathrm{b}}$ & $1.17 \pm 0.17^{\mathrm{b}}$ \\
FCR & $1.54 \pm 0.34^{\mathrm{a}}$ & $1.68 \pm 0.01^{\mathrm{a}}$ & $1.92 \pm 0.23^{\mathrm{a}}$ \\
\hline a, b, c different lowercase on superscript mean significant difference $(P<0.05)$
\end{tabular}

[60, 61], inhibiting vibrio [62-64] and promoting digestion $[65,66]$. The genus Aestuariibacter, which belongs to the family Alteromonadaceae, was proposed by Yi for strictly aerobic, chemoheterotrophic, salt-requiring and nitrate-reducing [67]. Its effect on shrimp is still unknown. Tenacibaculum genus has several species which are pathogen to fish [68-70]. The bacterial community of culture water had a great difference from that of bioreactors. And the function of most bacteria in culture water is not sure.

\section{Probiotics and potential pathogen}

The growth of the aquaculture industry is hampered by unpredictable mortalities, many of which are caused by pathogenic microorganisms. Bacterial diseases have been attributed to biological production bottlenecks in intensive aquaculture [71]. Besides a microbial community that purifies the water, microbiota in RAS can also harbor pathogens or produce off-flavor-causing compounds [72]. Because of a low dilution rate and high organic loading, pathogens might accumulate more in RAS biofilters than in single-pass systems [73]. Besides Vibrio as a traditional pathogen, Streptococcus sp. [74], Nautella italica, and Pseudoalteromonas piscicida [54] also have threats to shrimp. Frequent application of antibiotics

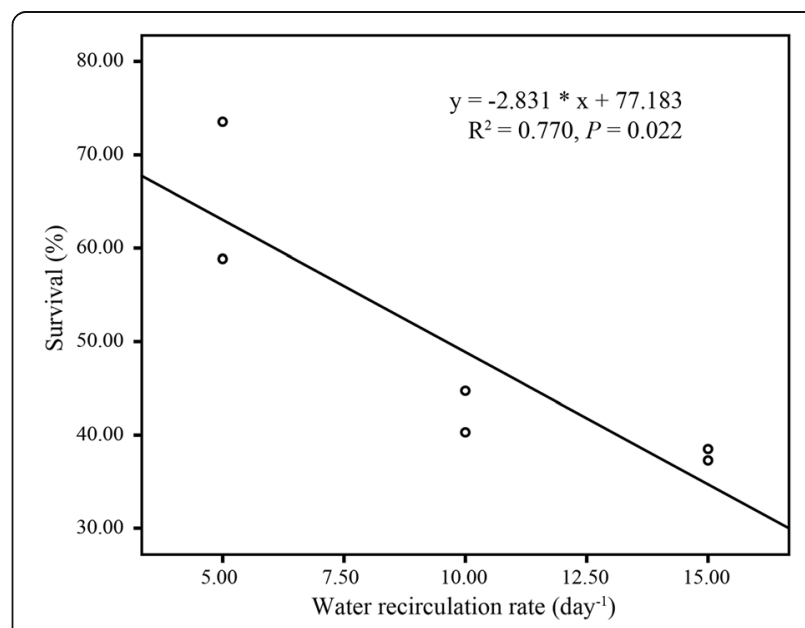

Fig. 8 Linear regression of shrimp survival on amount of water recirculation ratio 
might lead to antibiotic resistance and destroy bacterial community structure. The use of antimicrobials to control diseases should be limited in RAS, and more attention should be given to alternative approaches $[75,76]$. Probiotics is a safer and more effective method to manage bacteria and control pathogenic bacteria via competitive exclusion, producing a specific inhibitory substance, competition for nutrients, producing antagonist for quorum sensing mechanism and improving immunity [71]. The most commonly used probiotic species include Lactobacillus, Bacillus, Pseudomonas, nitrobacteria, etc. In addition, 'neutral bacteria' could also contribute to the stabilization of the microbial community and even play a primary role in biosecurity [77]. According to the result of bacteria composition, the proportion of probiotics was relatively low. And potential pathogen, especially Nautella in culture water, had a high frequency. Though the function of most bacteria in the systems is not sure, 'neutral bacteria' may take great contribution to the balance of potential pathogens and candidate probiotics.

\section{The effects of water recirculation on RAS}

Increasing the water recirculation ratio can increase the number of times water flows through the water treatment process, increase the hydraulic load, and improve the removal efficiency of solid particles and ammonia. Some studies have reported that shorter HRT is conducive to the purification of water quality $[24,78,79]$. Increasing the water recirculation ratio will increase the turbulence of the water. And the nitrification rate could be significantly improved by increasing the turbulence [80].

The effect of water recirculation ratio on ammonia removal is to change the number of times water flows through the bioreactor, on the other hand, to change the structure of the microbial community in the bioreactor. Water recirculation ratio was an important factor affecting microbial community structure $[14,17,21,79]$. The proportion of dominant groups showed a trend with the variety of water recirculation ratio in bioreactor and culture water. In the middle period of cultivation, the dominant family of bioreactor was Rhodobacteraceae, accounting for $30.2-49.6 \%$ of the community, which increased with the increase of water recirculation ratio (Fig. 2 a). At the end of cultivation, the dominant family of bioreactor was Phytophthoraceae, accounting for $16.0-30.1 \%$ of the community, which decreased with the increase of water recirculation ratio (Fig. 2 b). In the culture water, the dominant phylum was Proteobacteria, accounting for 77.9-96.4\%, which increased with the increase of water recirculation ratio (Fig. 4 a). And the dominant families and genus of culture water showed different trends with the variety of water recirculation ratio (Fig. 4 b, c). The microbial community of RASs was significantly changed by water recirculation ratio, which could be furtherly confirmed by UPGMA tree. UPGMA tree (Fig. 6) reflected the similarity of different samples. In bioreactors, $\mathrm{LC}$ and $\mathrm{MC}$ had more similarity, however in culture water, $\mathrm{HC}$ and $\mathrm{MC}$ had more similarity. In the bioreactor, increasing water recirculation ratio will increase the shear force on the surface of biofilm. Bacteria with strong adhesion ability can grow on the surface of the substrate in the bioreactor. In addition, the flow rate on the surface of biofilm also affects the absorption and utilization of nutrients by microorganisms in water. For microorganisms in culture water, water recirculation ratio will affect the number of times water passes through UV, resulting in the bacteria with stronger resistance to UV or more reproductive have more advantages.

Water recirculation ratio not only affects the dominant groups of microbial communities but also affects some functional microbial groups. Although there are only three kinds of nitrifying bacteria in the bioreactor, Nitrococcus, Nitrosomonas and Nitrospira, and their proportion in the microbial community was not significantly different among $\mathrm{LC}, \mathrm{MC}$ and $\mathrm{HC}$, the proportion of the three nitrifying bacteria in the community increased with the increasing of water recirculation ratio, which was $(0.6 \pm 0.5) \%,(0.9 \pm 0.4) \%$ and $(1.1 \pm 0.6) \%$, respectively. That is, the number of nitrifying bacteria was more under the high water recirculation ratio. For the Vibrio in bioreactor, its proportions in $\mathrm{LC}, \mathrm{MC}$ and $\mathrm{HC}$ were $(3.2 \pm 0.5) \%,(1.4 \pm 0.1) \%$ and $(0.5 \pm 0.0) \%$, respectively. The proportions of Vibrio in bioreactor were decreased with the increases in water recirculation rate $(P<0.05)$. For potential pathogen Nautella (Fig. 4 c), the proportion in the water of LC was significantly more than that in $\mathrm{MC}$ and $\mathrm{HC}(P<0.05)$. Increasing water recirculation ratio is beneficial to reducing the number of potential pathogens in bioreactors and aquaculture waters. The water recirculation ratio had a great effect on bacterial community structure, which could be a useful method to manage RAS.

Increasing water recirculation rate could improve water quality, reduce the number of pathogenic bacteria and promote shrimp growth. The proportion of potential pathogens Nautella and Tenacibaculum in culture water of LC treatment were higher than that in MC and $\mathrm{HC}$, which assumed to be the reason for lower SGR of shrimp in LC. The mean weight of shrimp in LC was significantly less than that in $\mathrm{MC}$ and $\mathrm{HC}$, but the survival, yield and FCR of LC were higher than MC and $\mathrm{HC}$. In view of the significantly different in the bacterial community among $\mathrm{LC}, \mathrm{MC}$ and $\mathrm{HC}$, there was an important relationship between shrimp culture and the bacterial community. The higher mean weight of shrimp 
in $\mathrm{MC}$ and $\mathrm{HC}$ was partly due to the higher mortality. On the other hand, a higher proportion of Pseudoalteromonas in $\mathrm{MC}$ and $\mathrm{HC}$ may promote the growth of shrimp. The higher mortality of shrimps in $\mathrm{MC}$ and $\mathrm{HC}$ maybe due to Aestuaribacter and Thalassotalea in view of their dominant status in the bacterial community of culture water, meanwhile their proportions were much higher than that in LC. Aestuariibacter and Thalassotalea belong to the Gammaproteobacteria class. At the class level, the proportions of Gammaproteobacteria in the bacterial community of culture water were 13.0, 61.1 and $79.6 \%$ in LC, MC and HC, respectively (Fig. 9). The high proportion of Gammaproteobacteria in culture water may be the reason for decreasing the survival rate of $L$. vannamei. In view of the unclear function of most bacteria in water, the relationship between bacteria in culture water and L. vannamei needs further study.

\section{Conclusions}

In the microbial community of RAS for $L$. vannamei, the most dominant phylum is Proteobacteria, followed by Planctomycetes, Bacteroidetes, Actinobacteria and Verrucomicrobia phylum. Rhodobacteraceae and Planctomycetaceae are the dominant families in the biofilter, while culture water community is dominated by Proteobacteria including the dominant families of Rhodobacteraceae, Aestuariibacter, Thalassotalea, and Pseudoalteromonas. Compared with culture water, bioreactor has a higher abundance and diversity of the microbial community and plays a more important role in the environmental regulation of RAS. Although several studies have been investigating the culture system microflora, the knowledge regarding the roles of environmental microbiota in RAS remains limited. The function of most dominant genera in RAS are unknowns and need further research.

Water recirculation rate as an important parameter of RAS affects the bacterial community of bioreactor and culture water. The proportions of dominant groups show a trend with the variety of water recirculation rate in bioreactor and culture water. The proportions of some microbial groups, such as nitrifying bacteria, Vibrio and Nautella, in the microbial community is also affected by the water recirculation rate. Water quality indexes such as ammonia, nitrite and turbidity decrease with the increasing of water recirculation rate. Though the growth rate and final weight of shrimp were the highest under medium water recirculation rate, the survival and yield have an inverse correlation with water recirculation rate. The higher mortality rate of shrimp under medium and high water recirculation rate assumed to be caused by the excessive Gammaproteobacteria in the bacterial community. The increasing water recirculation rate could change microbial community constitution, improve water quality, and promote shrimp growth, however, L. vannamei has better performance of survival and yield under low water recirculation rate. Water recirculation rate is an effective method to manage RAS of $L$. vannamei, and the impacts of water recirculation on RAS needs further study,

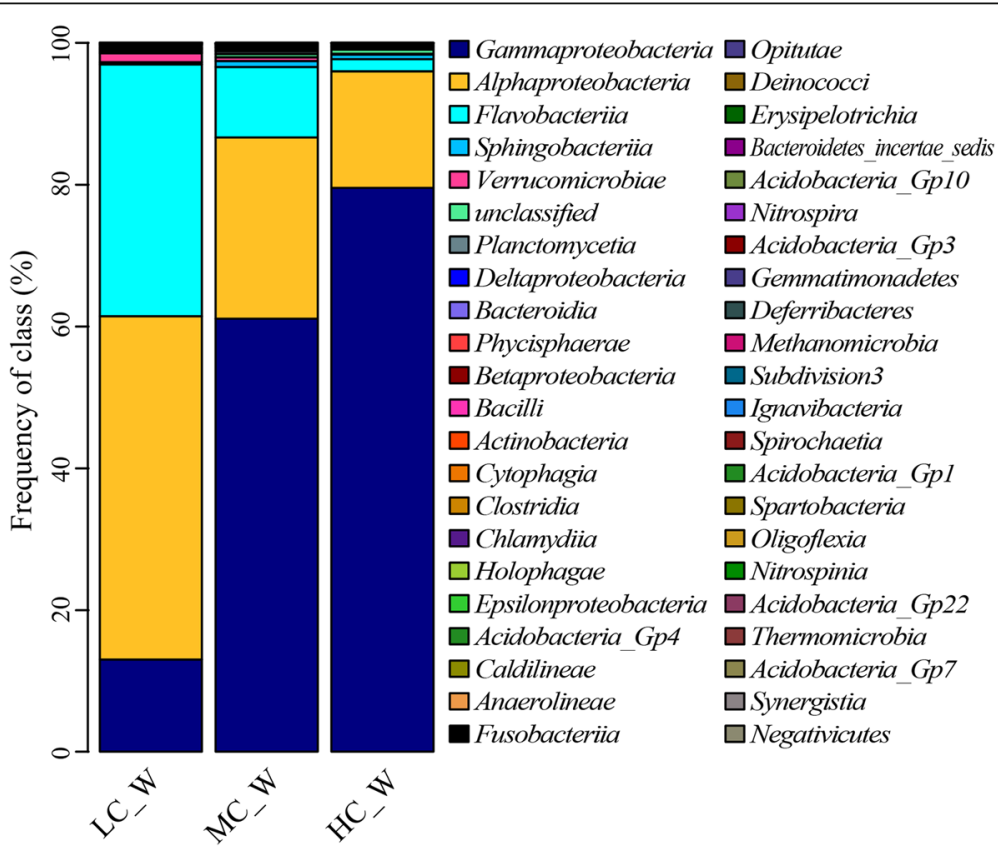

Fig. 9 Taxonomic assignment of bacteria in culture water at class level shown as a percentage of the total microbiota 
especially in the application of low level of water recirculation.

\section{Methods}

\section{Experimental systems}

The experiment lasted 91 days from June 2nd to September 1st. RASs was indoor and adopted natural lighting trough light-transmitting plate. Each RAS consisted of one circular fiberglass culture tank $\left(3.1 \mathrm{~m}^{3}\right)$ and one filter bag with $75 \mu \mathrm{m}$ pore size for particle removal, followed by a fixed bed bioreactor (FBBR, $0.6 \mathrm{~m}^{3}$ ) and a moving bed bioreactor (MBBR, $0.6 \mathrm{~m}^{3}$ ) for removal of toxic ammonia and nitrite, after which the water was disinfected by UV and returned to the culture tank (Fig. 10). The stock density is 1000 shrimp/tank (322ind/ $\mathrm{m}^{3}$ ). No water exchanged in the first 2 weeks; then water was exchanged twice a week with the water exchange rate $14-28 \%$.

\section{Experimental design}

Three water flow rates were set for the experiment with the water recirculation rate of 5,10 and 15 day $^{-1}$, representing low (LC), medium (MC) and high (HC) recirculation rate respectively. Each recirculation rate had two RASs. Shrimps were fed with formulated feed (42\% crude protein) five times a day. The feeding amount of each tank was the same. The feeding amount was $4 \%$ of total shrimp weight at the initial stage, and gradually increased with the growth of shrimps. Water samples were collected from the culture tank every week for the measurement of water quality to reflect the water environment [81]. One bacteria samples were collected from each bioreactor for the measurement of the microbial community at the medium-term and end. Besides, one bacteria sample in culture water was also collected via $0.22-\mu \mathrm{m}$-pore-diameter filter membrane at the end of culture from each system. For bacterial samples, one sample was taken from each RAS, i.e. two parallel bacterial samples were taken from each water recirculation ratio. Bacteria samples were stored at $-80^{\circ} \mathrm{C}$ before usage. At the end of culture, 20 shrimps were collected from each system for the measurement of individual weight.

\section{Measurements}

Shrimp weight was measured by electronic scales (Mettler Toledo, Shanghai, China). DO, pH, temperature and salinity were recorded with YSI (YSI Incorporated, Yellow Springs, OH, USA). Turbidity was measured by turbidimeter (Yuefeng, Shanghai, China). Total ammonia was measured by phenate method [81], nitrite was measured by $\mathrm{N}$-(1-naphthyl)-1, 2-diaminoethane dihydrochloride spectrophotometry [82], Vibrio number was enumerated by TCBS agar media [83-85] for reflecting the status of pathogenic microbes. The growth performance of shrimp was reflected by initial weight, final weight and specific growth rate $(\mathrm{SGR}=100 \times(\mathrm{Ln}$ (final weight) - Ln (initial weight)) / culture days).

Total DNA of bacterial samples was extracted using the TIANamp Bacteria DNA Kit (Tiangen Biotech, Beijing, China). The DNA concentration was determined using NanoDrop Spectrophotometer (Thermo Scientific, USA), and DNA integrity was confirmed by agarose gel electrophoresis. Microbial DNA was amplified by polymerase chain reaction for the $\mathrm{V} 3-\mathrm{V} 4$ region of the 16srRNA gene. After purification, samples were mixed in equal concentrations and sequenced by IlluminaMiSeq. The raw reads were deposited into the NCBI

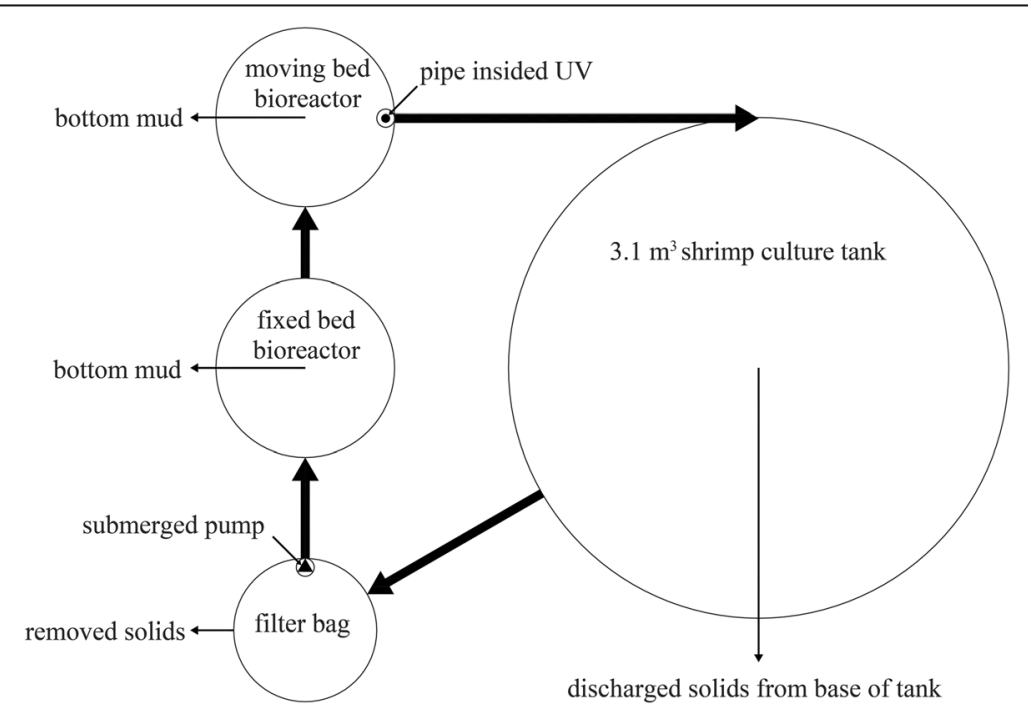

Fig. 10 Summary diagram of an individual experimental recirculating aquaculture system employed in this study 
Sequence Read Archive (SRA) database (Accession Number: SRP214732).

\section{Statistical analysis}

The statistical analysis was performed using SPSS program version 13.0 (SPSS, Chicago, IL, USA), an independent samples T-test was conducted to compare the significant differences among the systems with different water recirculation rates on water quality and shrimp growth, one-way ANOVA was conducted on the change of water recirculation rates among the systems, and Pearson correlation analysis and linear regression analysis were conducted to reveal the relationship among shrimp growth, water recirculation rate and water quality indexes.

These sequences of bacteria samples were clustered using Usearch into operational taxonomic units (OTUs), based on $97 \%$ sequence similarity. The sequences were aligned against the bacterial NCBI database for taxonomic classification. Alpha-diversity indices (Chao index and Simpson index) for each sample were calculated using $R$ [86]. The Chao1 index quantifying species richness was calculated using the formula:

$$
S_{\text {Chao1 }}=S_{\text {obs }}+n_{1}\left(n_{1}-1\right) /\left(2 \times\left(n_{2}+1\right)\right)
$$

Where $S_{\text {obs }}$ is the observed number of OTUs, $n_{1}$ is the number of OTUs with only one sequence, and $n_{2}$ is the number of OTUs with only two sequences [87]. The Simpson index quantifying community diversity was determined as:

$$
D_{\text {Simpson }}=\left(\sum_{i=1}^{S_{o b s}} n i(n i-1)\right) /(N(N-1))
$$

Where $S_{\text {obs }}$ is the number of observed OTUs, $n_{\mathrm{i}}$ is the number of individuals in the $i$ th OTU, and $N$ is the total number of individuals in the community [88]. Based on the unweighted UniFrac distance metric [89] estimated by QIIME [90], principal co-ordinate analysis (PCoA) and cluster analysis $(\mathrm{CA})$ was conducted using the unweighted pair group method with arithmetic mean (UPGMAM) method to estimate $\beta$-diversity and visualize microbial community diversity among samples [91]

\section{Acknowledgements}

The authors would like to acknowledge Dedong Song for the design of the culture systems. The sequencing service was provided by the Sangon Biotech (Shanghai) Co., Ltd.

\section{Authors' contributions}

ZC, JL, and FZ had the initial idea for the study. ZC made substantial contribution to the conception of the study, and contributed to writing the manuscript. ZQC contributed to the modification of manuscript. LZ, YJ, and $\mathrm{HG}$ helped with the management and monitoring of the culture systems. $J \mathrm{~L}$ as a project leader of the project that has financed this research, contributed to the exposure planning and execution. SC provided experimental sites and guidance. XS helped with the design of the culture systems. All authors read and approved the final manuscript.

\section{Funding}

This study was supported by China Agriculture Research System-48, Taishan Industrial Leader Talent Project of Shandong Province (LJNY2015002), National Marine Economy Innovation and Development Demonstration City Project (Qingdao 2016), the Blue Industrial Leader Talent Support Project of Shandong Province, and by the Projects of International Exchange and Cooperation in Agriculture, Ministry of Agriculture and Rural Affairs of ChinaScience, Technology and Innovation Cooperation in Aquaculture with Tropical Countries.

\section{Availability of data and materials}

All supporting data generated during this study are included in this published article.

\section{Ethics approval and consent to participate}

The study protocol was approved by the Institutional Animal Care and Use Committee, Yellow Sea Fisheries Research Institute, Chinese Academy of Fishery Sciences, China.

Consent for publication

Not applicable.

\section{Competing interests}

The authors declare that they have no competing interests.

\section{Author details}

${ }^{1}$ Key Laboratory for Sustainable Development of Marine Fisheries, Ministry of Agriculture, Yellow Sea Fisheries Research Institute, Chinese Academy of Fishery Sciences, Qingdao 266071, People's Republic of China. ${ }^{2}$ Fisheries College, Ocean University of China, Qingdao 266003, People's Republic of China. ${ }^{3}$ Qingdao Excellent Ocean Group Co., Ltd, Qingdao 266400, People's Republic of China.

Received: 28 April 2018 Accepted: 4 August 2019

Published online: 19 August 2019

\section{References}

1. Yogev U, Sowers KR, Mozes N, Gross A. Nitrogen and carbon balance in a novel near-zero water exchange saline recirculating aquaculture system. Aquaculture. 2017;467:118-26.

2. Samocha TM, Lawrence AL, Pooser D. Growth and survival of juvenile Penaeus vannamei in low salinity water in a semi-closed recirculating system. The Israeli journal of aquaculture = Bamidgeh. 1998;50(2):55-9.

3. Baron-Sevilla B, Buckle-Ramirez LF, Hernandez-Rodriguez M. Intensive culture of Litopenaeus vannamei Boone 1931, in a recirculating seawater system. Ciencias Marinas. 2004;30(1B):179-88.

4. Mishra JK, Samocha TM, Patnaik S, Speed M, Gandy RL, Ali A-M. Performance of an intensive nursery system for the Pacific white shrimp Litopenaeus vannamei, under limited discharge condition. Aquac Eng. 2008; 38(1):2-15.

5. Cheng B, Liu Y, Yang H, Song Y, Li X. Effect of copper on the growth of shrimps Litopenaeus vannamei: water parameters and copper budget in a recirculating system. Chin J Oceanol Limnol. 2014;32(5):1092-104.

6. FAO: The State of World Fisheries and Aquaculture. State of World Fisheries \& Aquaculture 2012:36-40.

7. Primavera JH. Tropical shrimp farming and its sustainability: 1998 .

8. Thakur DP, Lin CK. Water quality and nutrient budget in closed shrimp (Penaeus monodon) culture systems. Aquac Eng. 2003:27(3):159-76.

9. Cohen JM, Samocha TM, Fox JM, Gandy RL, Lawrence AL. Characterization of water quality factors during intensive raceway production of juvenile Litopenaeus vannamei using limited discharge and biosecure management tools. Aquac Eng. 2005;32(3-4):425-42.

10. Bartelme RP, McLellan SL, Newton RJ. Freshwater recirculating aquaculture system operations drive biofilter bacterial community shifts around a stable nitrifying consortium of Ammonia-oxidizing archaea and Comammox Nitrospira. Front Microbiol. 2017;8:101

11. Monds RD, O'Toole GA. The developmental model of microbial biofilms: ten years of a paradigm up for review. Trends Microbiol. 2009;17(2):73-87.

12. Schreier HJ, Mirzoyan N, Saito K. Microbial diversity of biological filters in recirculating aquaculture systems. Curr Opin Biotechnol. 2010;21(3):318-25. 
13. Ruan Y-J, Guo X-S, Ye Z-Y, Liu Y, Zhu S-M. Bacterial community analysis of different sections of a biofilter in a full-scale marine recirculating aquaculture system. N Am J Aquac. 2015;77(3):318-26.

14. Schneider $\mathrm{O}$, Chabrillon-Popelka M, Smidt H, Haenen O, Sereti V, Eding EH, Verreth JAJ. HRT and nutrients affect bacterial communities grown on recirculation aquaculture system effluents. FEMS Microbiol Ecol. 2007;60(2): 207-19

15. Brown MN, Briones A, Diana J, Raskin L. Ammonia-oxidizing archaea and nitrite-oxidizing nitrospiras in the biofilter of a shrimp recirculating aquaculture system. FEMS Microbiol Ecol. 2013;83(1):17-25.

16. Huang Z, Wan R, Song X, Liu Y, Hallerman E, Dong D, Zhai J, Zhang H, Sun L. Metagenomic analysis shows diverse, distinct bacterial communities in biofilters among different marine recirculating aquaculture systems. Aquac Int. 2016;24(5):1393-408.

17. Deng Y-L, Ruan Y-J, Zhu S-M, Guo X-S, Han Z-Y, Ye Z-Y, Liu G, Shi M-M. The impact of DO and salinity on microbial community in poly (butylene succinate) denitrification reactors for recirculating aquaculture system wastewater treatment. AMB Express. 2017;7:113.

18. Xiong J, Zhu J, Wang K, Wang X, Ye X, Liu L, Zhao Q, Hou M, Qiuqian L, Zhang D. The temporal scaling of Bacterioplankton composition: high turnover and predictability during shrimp cultivation. Microb Ecol. 2014; 67(2):256-64.

19. Rafael Martinez-Cordova L, Martinez-Porchas M, Antonio Porchas-Cornejo M, Gollas-Galvan T, Scheuren-Acevedo S, Antonio Arvayo M, Antonio LopezElias J, Antonio Lopez-Torres M. Bacterial diversity studied by nextgeneration sequencing in a mature phototrophic Navicula sp-based biofilm promoted into a shrimp culture system. Aquac Res. 2017:48(5):2047-54.

20. Hou D, Huang Z, Zeng S, Liu J, Wei D, Deng X, Weng S, He Z, He J. Environmental factors shape water microbial community Structureand Functionin shrimp cultural enclosure ecosystems. Front Microbiol. 2017;8.

21. Gonzalez-Martinez A, Pesciaroli C, Martinez-Toledo MV, Hontoria E, Gonzalez-Lopez J, Osorio F. Study of nitrifying microbial communities in a partial-nitritation bioreactor. Ecol Eng. 2014;64:443-50.

22. Cydzik-Kwiatkowska A, Rusanowska P, Zielinska M, Bernat K, WojnowskaBaryla I. Structure of nitrogen-converting communities induced by hydraulic retention time and $\mathrm{COD} / \mathrm{N}$ ratio in constantly aerated granular sludge reactors treating digester supernatant. Bioresour Technol. 2014;154:162-70.

23. Cydzik-Kwiatkowska A, Wojnowska-Barya I. Nitrogen-converting communities in aerobic granules at different hydraulic retention times (HRTs) and operational modes. World J Microbiol Biotechnol. 2015;31(1): 75-83.

24. Seo JK, Jung $\mathbb{H}$, Kim MR, Kim BJ, Nam SW, Kim SK. Nitrification performance of nitrifiers immobilized in PVA (polyvinyl alcohol) for a marine recirculating aquarium system. Aquac Eng. 2001;24(3):181-94.

25. Bui Xuan T, Berg H, Le Nguyen TN, Chau Thi D. Effects of hydraulic retention time on organic and nitrogen removal in a sponge-membrane bioreactor. Environ Eng Sci. 2013;30(4):194-9.

26. Singh $\mathrm{S}$, Ebeling J, Wheaton F. Water quality trials in four recirculating aquacultural system configurations. Aquac Eng. 1999;20(2):75-84.

27. D'orbcastel ER, Blancheton J-P, Belaud A. Water quality and rainbow trout performance in a Danish Model Farm recirculating system: Comparison with a flow through system. Aquac Eng. 2009;40(3):135-43.

28. Huang Z, Song $X$, Zheng $Y$, Peng L, Wan R, Lane T, Zhai J, Hallerman E, Dong $D$. Design and evaluation of a commercial recirculating system for half-smooth tongue sole (Cynoglossus semilaevis) production. Aquac Eng. 2013;54:104-9.

29. Kolarevic J, Aas-Hansen O, Espmark A, Baeverfjord G, Terjesen BF, Damsgard $B$. The use of acoustic acceleration transmitter tags for monitoring of Atlantic salmon swimming activity in recirculating aquaculture systems (RAS). Aquac Eng. 2016;72-73:30-9.

30. Lin YC, Chen JC. Acute toxicity of ammonia on Litopenaeus vannamei Boone juveniles at different salinity levels. J Exp Mar Biol Ecol. 2001;259(1):109-19.

31. Lin YC, Chen JC. Acute toxicity of nitrite on Litopenaeus vannamei (Boone) juveniles at different salinity levels. Aquaculture. 2003;224(1-4):193-201.

32. Lee D-E, Lee J, Kim Y-M, Myeong J-I, Kim K-H. Uncultured bacterial diversity in a seawater recirculating aquaculture system revealed by $16 \mathrm{~S}$ rRNA gene amplicon sequencing. J Microbiol. 2016;54(4):296-304.

33. Wietz M, Hall MR, Hoj L. Effects of seawater ozonation on biofilm development in aquaculture tanks. Syst Appl Microbiol. 2009;32(4):266-77.

34. Rud I, Kolarevic J, Holan AB, Berget I, Calabrese S, Terjesen BF. Deepsequencing of the bacterial microbiota in commercial-scale recirculating and semi-closed aquaculture systems for Atlantic salmon post-smolt production. Aquac Eng. 2017;78:50-62.

35. Tang Y, Tao P, Tan J, Mu H, Peng L, Yang D, Tong S, Chen L. Identification of bacterial community composition in freshwater aquaculture system farming of Litopenaeus vannamei reveals distinct temperature-driven patterns. Int J Mol Sci. 2014;15(8):13663-80.

36. Michaud L, Lo Giudice A, Interdonato F, Triplet S, Ying L, Blancheton JP. C/N ratio-induced structural shift of bacterial communities inside lab-scale aquaculture biofilters. Aquac Eng. 2014;58:77-87.

37. Martins P, Cleary DFR, Pires ACC, Rodrigues AM, Quintino V, Calado R, Gomes NCM. Molecular Analysis of Bacterial Communities and Detection of Potential Pathogens in a Recirculating Aquaculture System for Scophthalmus maximus and Solea senegalensis. PLoS One. 2013;8:11.

38. Leonard N, Blancheton JP, Guiraud JP. Populations of heterotrophic bacteria in an experimental recirculating aquaculture system. Aquac Eng. 2000;22(12):109-20.

39. Leonard N, Guiraud JP, Gasset E, Cailleres JP, Blancheton JP. Bacteria and nutrients - nitrogen and carbon - in a recirculating system for sea bass production. Aquac Eng. 2002;26(2):111-27.

40. Michaud L, Blancheton JP, Bruni V, Piedrahita R. Effect of particulate organic carbon on heterotrophic bacterial populations and nitrification efficiency in biological filters. Aquac Eng. 2006;34(3):224-33.

41. Martins CIM, Eding EH, Verdegem MCJ, Heinsbroek LTN, Schneider O, Blancheton JP, d'Orbcastel ER, Verreth JAJ. New developments in recirculating aquaculture systems in Europe: a perspective on environmental sustainability. Aquac Eng. 2010;43(3):83-93.

42. Rurangwa $\mathrm{E}$, Verdegem MCJ. Microorganisms in recirculating aquaculture systems and their management. Rev Aquac. 2015;7(2):117-30.

43. Tal $Y$, Watts JEM, Schreier HJ. Anaerobic ammonium-oxidizing (anammox) bacteria and associated activity in fixed-film biofilters of a marine recirculating aquaculture system. Appl Environ Microbiol. 2006;72(4):2896-904.

44. Choi A, Cho H, Kim S-H, Thamdrup B, Lee S, Hyun J-H. Rates of N-2 production and diversity and abundance of functional genes associated with denitrification and anaerobic ammonium oxidation in the sediment of the Amundsen Sea polynya, Antarctica. Deep-Sea Research Part li-Topical Studies in Oceanography. 2016;123:113-25.

45. Lidbury IDEA, Murrell JC, Chen Y. Trimethylamine and trimethylamine Noxide are supplementary energy sources for a marine heterotrophic bacterium: implications for marine carbon and nitrogen cycling. ISME J. 2015;9(3):760-9.

46. Scheuner C, Tindall BJ, Lu M, Nolan M, Lapidus A, Cheng J-F, Goodwin L, Pitluck S, Huntemann M, Liolios K, et al. Complete genome sequence of Planctomyces brasiliensis type strain (DSM 5305(T)), phylogenomic analysis and reclassification of Planctomycetes including the descriptions of Gimesia gen. nov., Planctopirus gen. nov and Rubinisphaera gen. nov and emended descriptions of the order Planctomycetales and the family Planctomycetaceae. Stand Genomic Sci. 2014;9:1.

47. Kohn T, Heuer A, Jogler M, Vollmers J, Boedeker C, Bunk B, Rast P, Borchert D, Gloeckner I, Freese HM, et al. Fuerstia marisgermanicae gen. nov., sp nov. an Unusual Member of the Phylum Planctomycetes from the German Wadden Sea. Front Microbiol. 2016:7.

48. Pedersen L-F, Pedersen PB, Nielsen JL, Nielsen PH. Peracetic acid degradation and effects on nitrification in recirculating aquaculture systems. Aquaculture. 2009;296(3-4):246-54.

49. Foesel BU, Gieseke A, Schwermer C, Stief P, Koch L, Cytryn E, de la Torre JR, van Rijn J, Minz D, Drake HL, et al. Nitrosomonas Nm143-like ammonia oxidizers and Nitrospira marina-like nitrite oxidizers dominate the nitrifier community in a marine aquaculture biofilm. FEMS Microbiol Ecol. 2008; 63(2):192-204.

50. Urakawa H, Tajima Y, Numata Y, Tsuneda S. Low temperature decreases the phylogenetic diversity of ammonia-oxidizing archaea and bacteria in aquarium biofiltration systems. Appl Environ Microbiol. 2008;74(3):894-900.

51. Bauld J, Staley JT. Planctomyces maris sp. nov.: a marine isolate of the Planctomyces-Blastocaulis group of budding Bacteria. J Gen Microbiol. 1976; 97(1):45-55

52. Schlesner H, Rensmann C, Tindall BJ, Gade D, Rabus R, Pfeiffer S, Hirsch P. Taxonomic heterogeneity within the Planctomycetales as derived by DNADNA hybridization, description of Rhodopirellula baltica gen. nov., sp nov., transfer of Pirellula marina to the genus Blastopirellula gen. nov as Blastopirellula marina comb. nov and emended description of the genus Pirellula. Int J Syst Evol Microbiol. 2004;54:1567-80. 
53. Yoon B-J, Oh D-C. Spongiibacterium flavum gen. nov., sp nov., a member of the family Flavobacteriaceae isolated from the marine sponge Halichondria oshoro, and emended descriptions of the genera Croceitalea and Flagellimonas. Int J Syst Evol Microbiol. 2012;62:1158-64.

54. Zheng Y, Yu M, Liu Y, Su Y, Xu T, Yu M, Zhang X-H. Comparison of cultivable bacterial communities associated with Pacific white shrimp (Litopenaeus vannamei) larvae at different health statuses and growth stages. Aquaculture. 2016;451:163-9.

55. Vandecandelaere I, Nercessian O, Segaert E, Achouak W, Mollica A, Faimali $M$, Vandamme $P$. Nautella italica gen. nov., sp nov., isolated from a marine electroactive biofilm. Int J Syst Evol Microbiol. 2009;59:811-7.

56. Zheng Y, Yu M, Liu J, Qiao Y, Wang L, Li Z, Zhang X-H, Yu M. Bacterial community associated with healthy and diseased Pacific white shrimp (Litopenaeus vannamei) larvae and rearing water across different growth stages. Front Microbiol. 2017;8

57. Zhang Y, Tang K, Shi X, Zhang X-H. Description of Thalassotalea piscium gen. nov., sp nov., isolated from flounder (Paralichthys olivaceus), reclassification of four species of the genus Thalassomonas as members of the genus Thalassotalea gen. nov and emended description of the genus Thalassomonas. Int J Syst Evol Microbiol. 2014;64:1223-8.

58. Park S, Jung Y-T, Kang C-H, Park J-M, Yoon J-H. Thalassotalea ponticola sp nov., isolated from seawater, reclassification of Thalassomonas fusca as Thalassotalea fusca comb. nov and emended description of the genus Thalassotalea. Int J Syst Evol Microbiol. 2014;64:3676-82.

59. Hou T-T, Liu Y, Zhong Z-P, Liu H-C, Liu Z-P. Thalassotalea marina sp nov., isolated from a marine recirculating aquaculture system, reclassification of Thalassomonas eurytherma as Thalassotalea eurytherma comb. nov and emended description of the genus Thalassotalea. Int J Syst Evol Microbiol. 2015;65:4710-5.

60. Hjelm M, Bergh O, Riaza A, Nielsen J, Melchiorsen J, Jensen S, Duncan H, Ahrens P, Birkbeck H, Gram L. Selection and identification of autochthonous potential probiotic bacteria from turbot larvae (Scophthalmus maximus) rearing units. Syst Appl Microbiol. 2004;27(3):360-71.

61. Pham D, Ansquer D, Chevalier A, Dauga C, Peyramale A, Wabete N, Labreuche Y. Selection and characterization of potential probiotic bacteria for Litopenaeus stylirostris shrimp hatcheries in New Caledonia. Aquaculture. 2014;432:475-82.

62. del Castillo CS, Wahid MI, Yoshikawa T, Sakata T. Isolation and inhibitory effect of anti-Vibrio substances from Pseudoalteromonas sp A1-J11 isolated from the coastal sea water of Kagoshima Bay. Fish Sci. 2008;74(1):174-9.

63. del Castillo CS, Yoshikawa T, Hashimoto M, Sakata T. Correlation between chemical structures and inhibitory activities of anti-bacterial substances from marine Pseudoalteromonas sp A1-J11. Fish Pathology. 2008;43(2):65-71.

64. Fjellheim AJ, Klinkenberg G, Skjermo J, Aasen IM, Vadstein O. Selection of candidate probionts by two different screening strategies from Atlantic cod (Gadus morhua L.) larvae. Vet Microbiol. 2010;144(1-2):153-9.

65. Tuyub Tzuc J, Rendiz Escalante D, Rojas Herrera R, Gaxiola Cortes G, Arena Ortiz ML: Microbiota from Litopenaeus vannamei: digestive tract microbial community of Pacific white shrimp (Litopenaeus vannamei). Springerplus 2014, 3.

66. Leyton Y, Sayes C, Mejias C, Abarca M, Wilson R, Riquelme C. Increased larval survival of Seriola lalandi using Pseudoalteromonas sp as probiotics. Revista De Biologia Marina Y Oceanografia. 2017:52(1):95-101.

67. Yi HN, Bae KS, Chun J. Aestuariibacter salexigens gen. nov., sp nov and Aestuariibacter halophilus sp nov., isolated from tidal flat sediment, and emended description of Alteromonas macleodii. Int J Syst Evol Microbiol. 2004:54:571-6

68. Olsen AB, Gulla S, Steinum T, Colquhoun DJ, Nilsen HK, Duchaud E. Multilocus sequence analysis reveals extensive genetic variety within Tenacibaculum spp. associated with ulcers in sea-farmed fish in Norway. Vet Microbiol. 2017;205:39-45.

69. Avendano-Herrera R, Toranzo AE, Magarinos B. Tenacibaculosis infection in marine fish caused by Tenacibaculum maritimum: a review. Dis Aquat Org. 2006;71(3):255-66.

70. Pineiro-Vidal M, Riaza A, Santos Y. Tenacibaculum discolor sp nov and Tenacibaculum gallaicum sp nov., isolated from sole (Solea senegalensis) and turbot (Psetta maxima) culture systems. Int J Syst Evol Microbiol. 2008:58:21-5.

71. Zorriehzahra MJ, Delshad ST, Adel M, Tiwari R, Karthik K, Dhama K, Lazado CC. Probiotics as beneficial microbes in aquaculture: an update on their multiple modes of action: a review. Vet Q. 2016;36(4):228-41.
72. Burr GS, Wolters WR, Schrader KK, Summerfelt ST. Impact of depuration of earthy-musty off-flavors on fillet quality of Atlantic salmon, Salmo salar, cultured in a recirculating aquaculture system. Aquac Eng. 2012;50:28-36.

73. Sharrer MJ, Summerfelt ST, Bullock GL, Gleason LE, Taeuber J. Inactivation of bacteria using ultraviolet irradiation in a recirculating salmonid culture system. Aquac Eng. 2005;33(2):135-49.

74. Hasson KW, Wyld EM, Fan Y, Lingsweiller SW, Weaver SJ, Cheng J, Varner PW. Streptococcosis in farmed Litopenaeus vannamei: a new emerging bacterial disease of penaeid shrimp. Dis Aquat Org. 2009;86(2):93-106.

75. Gatesoupe FJ. The use of probiotics in aquaculture. Aquaculture. 1999; 180(1-2):147-65.

76. Irianto A, Austin B. Probiotics in aquaculture. J Fish Dis. 2002;25(11):633-42.

77. Michaud L, Lo Giudice A, Troussellier M, Smedile F, Bruni V, Blancheton JP. Phylogenetic characterization of the heterotrophic bacterial communities inhabiting a marine recirculating aquaculture system. J Appl Microbiol. 2009; 107(6):1935-46.

78. Kim SK, Kong I, Lee BH, Kang L, Lee MG, Suh KH. Removal of ammonium-N from a recirculation aquacultural system using an immobilized nitrifier. Aquac Eng. 2000;21(3):139-50.

79. Gao DW, Tao Y, An R. Digested sewage treatment using membranebased process at different hydraulic retention times. Desalination. 2012; 286(1):187-92.

80. Chen S, Ling J, Blancheton JP. Nitrification kinetics of biofilm as affected by water quality factors. Aquac Eng. 2006;34(3):179-97.

81. APHA: Standard methods for the examination of water and wastewater: APHA American Public Health Association; 1981.

82. Bendschneider K, Robinson RJ. A new spectrophotometric method for the determination of nitrite in sea water; 1952.

83. Turner JW, Good B, Cole D, Lipp EK. Plankton composition and environmental factors contribute to Vibrio seasonality. ISME J. 2009;3(9): 1082-92.

84. Thompson FL, lida T, Swings J. Biodiversity of vibrios. Microbiol Mol Biol Rev. 2004:68(3):403-+.

85. Pfeffer CS, Hite MF, Oliver JD. Ecology of Vibrio vulnificus in estuarine waters of eastern North Carolina. Appl Environ Microbiol. 2003;69(6):3526-31.

86. Jurasinski G, Retzer V, Beierkuhnlein C. Inventory, differentiation, and proportional diversity: a consistent terminology for quantifying species diversity. Oecologia. 2009;159(1):15-26.

87. Chao A. Nonparametric estimation of the number of classes in a population. Scand J Stat. 1984;11(4):265-70

88. Simpson EH. The measurement of diversity. Nature. 1949;163(4148):688.

89. Peiffer JA, Spor A, Koren O, Jin Z, Tringe SG, Dangl JL, Buckler ES, Ley RE. Diversity and heritability of the maize rhizosphere microbiome under field conditions. Proc Natl Acad Sci U S A. 2013;110(16):6548-53.

90. Caporaso JG, Kuczynski J, Stombaugh J, Bittinger K, Bushman FD, Costello EK, Fierer N, Pena AG, Goodrich JK, Gordon Jl, et al. QIIME allows analysis of high-throughput community sequencing data. Nat Methods. 2010;7(5):335-6.

91. Lozupone C, Knight R. UniFrac: a new phylogenetic method for comparing microbial communities. Appl Environ Microbiol. 2005;71(12):8228-35.

\section{Publisher's Note}

Springer Nature remains neutral with regard to jurisdictional claims in published maps and institutional affiliations.

Ready to submit your research? Choose BMC and benefit from:

- fast, convenient online submission

- thorough peer review by experienced researchers in your field

- rapid publication on acceptance

- support for research data, including large and complex data types

- gold Open Access which fosters wider collaboration and increased citations

- maximum visibility for your research: over $100 \mathrm{M}$ website views per year

At $\mathrm{BMC}$, research is always in progress.

Learn more biomedcentral.com/submission 